\title{
Inducing Fear
}

\section{Ami Harbin ${ }^{1}$}

Accepted: 7 July 2020 / Published online: 15 July 2020

(C) Springer Nature B.V. 2020

\begin{abstract}
This paper offers an ethical consideration of how fear can be a tool of agents, used to deliberately shift people away from existing beliefs, commitments, or habits, or towards new ones. It contends that properly understanding the ethical dimensions of such uses of fear depends in part on a clear understanding of the dynamics of disorientation that can be involved in such uses. Section two begins with a clarification of the connections between fear, orientation, and disorientation. It suggests that experiences of fear are in some cases either orienting or disorienting, and that the disorienting aspects of fear are in need of more attention. Section three shows how experiences of fear can be tools - they can be cultivated and wielded by agents deliberately for multiple reasons, including sometimes in order to disorient or re-orient others. Section four turns to a moral evaluation of these uses of fear, attending specifically to why the dynamics of disorientation and orientation often involved in experiences of fear are important for understanding the moral status of uses of fear.
\end{abstract}

Keywords Disorientation $\cdot$ Fear $\cdot$ Manipulation $\cdot$ Paternalism

\section{Introduction}

In this paper, I consider the ways in which fear can be a tool of agents, used to deliberately shift other people away from existing beliefs, commitments, or habits, or towards new ones. I offer an account of how fear may be cultivated with the end goal of either orienting or disorienting, and I provide a moral evaluation of these uses of fear. I suggest that such an evaluation depends in part on first establishing a clear understanding of the dynamics of disorientation that can be involved in such uses.

In section two I begin with a clarification of the connections between fear, orientation, and disorientation. I suggest that experiences of fear are in some cases either orienting or disorienting, and that the disorienting aspects of fear are in need of more attention. In section

Ami Harbin

aharbin@oakland.edu

1 Department of Philosophy, Oakland University, Rochester, MI 48309, USA 
three, I show how experiences of fear can be tools - they can be cultivated and wielded by agents deliberately for multiple reasons, including sometimes in order to disorient or re-orient others. In section four, I turn to a moral evaluation of these uses of fear, attending specifically to why the dynamics of disorientation and orientation often involved in experiences of fear are important for understanding the moral status of these uses.

\section{Fear, Orientation, and Disorientation}

\subsection{Characteristics of Fear}

Intense emotions such as fear, anger, and shame can alter individuals' capacities for decisionmaking, emotional regulation, and relating to others. As Heilman and colleagues note, "It is well established that emotion plays a key role in human social and economic decision making...People evaluate objective features of alternatives such as expected return in a subjective way... and emotions are understood to influence these subjective evaluations" (Heilman et al. 2010, 257). The history of neuroscientific research on fear has developed extensively over the last 50 years, in particular focusing on the neural structures involved in fear, and how fear can affect decision-making processes. As Hartley and Phelps summarize, "The neurocircuitry supporting fear conditioning has been extensively investigated in animal models and humans and highlights the central role of the amygdala in fear acquisition, storage, and expression" (Hartley and Phelps 2012, 113). Joseph LeDoux's seminal research starting in the 1970s has provided the groundwork for much clearer understandings of the role of the amygdala (a subcortical structure in the medial temporal lobe) in experiences of fear and anxiety (see LeDoux 1996). As Johnston and Olson explain, LeDoux's early research on fear conditioning in rats, involving pairing auditory tones with brief electric shocks, revealed the key role of the amygdala in detecting threats and cueing the body to respond with an excess of caution (Johnston and Olson 2015, 84, 70). The amygdala triggers the release of stress hormones epinephrine and cortisol, which increase heart rates, respiration, and blood pressure, helping the body prepare to enact fight or flight. Very often the effects of fear on cognition are beyond our control. As Johnson and Olson note, "It's easier for emotions to invade our thought processes than it is for us to take cognitive control of our emotions because the amygdala is better at driving the prefrontal cortex than vice versa" (Johnston and Olson 2015, 83).

Although there may be some experiences of fear that agents find tolerable, enjoyable, or even worth seeking (e.g., horror movies, haunted houses, roller coasters), experiences of genuine and sustained fear for the wellbeing of one's self, one's loved ones, or fear for the security of one's environment are all forms of suffering. To be fearful in these senses is to suffer.

In humans, these physiological components of fear experiences have been shown to alter a variety of everyday cognitive processes. Fear has been shown to alter processes of visual perception (Phelps et al. 2006), risk perception (Lerner and Keltner 2001), and information uptake (Bohner and Weinerth 2001). Fear has been shown to sometimes radically alter individuals' practices of decision-making (Skitka et al. 2006). Perhaps unsurprisingly, experiences of fear sometimes prompt individuals to make more risk-averse decisions, and to be more pessimistic about the likelihood of positive events in the future (Lerner and Keltner 2001). To take a specific example, Chanel and Chichilnisky (2009) have shown that fear in some cases alters study subjects' capacity for making decisions by making them excessively focused on the possibility of catastrophic events. This means that fearful subjects are not able 
to proceed in decision-making as they ordinarily would, because they are held up by fear of risks or of devastating outcomes.

As such, fear can certainly have serious effects on belief, and in some cases, can have epistemic costs. In conjunction with the ways fears can augment what agents see, perceive as dangerous, how agents process information, and make decisions, fears can certainly alter individuals' beliefs in relation to processes of perception, information-processing, and decision-making. If a fearful individual is more likely to visually process only some parts of their environment, or to be able to take in more limited amounts of new information, this can limit what they know about their environment. If a fearful agent is more likely to perceive some object or event as risky than their non-fearful counterpart, their beliefs about that object or event may not accurately reflect the actual risk posed. Fear can have serious implications for what agents believe, and for how accurately those beliefs reflect reality. In some cases, this can amount to epistemic damage.

In addition to altering subjects' capacities for decision-making, fear can disrupt agents' ways of relating to others: subjects can become more suspicious of others, less trusting, and more circumspect (Ray and Vanstone 2009). Both fears directly related to one's relationship (e.g., fears of the person with whom one is in relationship, or fears that something bad may happen to them) and unrelated fears (e.g., fears of some other perceived danger) can stall one's ability to relate to others: they can distract individuals, make one unable to focus on treating others well, or disrupt one's capacity for trusting ways of relating.

\subsection{Experiences of Fear Can Be Disorienting}

If fear can have these effects, causing suffering, fundamentally altering even one's most basic capacities for visual perception, risk perception, information uptake, making subjects less sure of themselves and their futures, and making it difficult or impossible to relate to others in practiced ways, it seems unsurprising that serious experiences of fear can, in some instances, be disorienting. In addition to the ways fears can disrupt these foundational capacities, they can also make one question who one is, and how one should continue to act in everyday life.

I have elsewhere described disorientations as "sustained, difficult experiences that make it hard to go on" (Harbin 2016, 17 ). On my view, disorientations regularly follow devastating experiences like the loss of a loved one, serious illness, trauma, or oppression, and they can also follow more neutral or positive events like migration, feminist education, queer identification, or consciousness-raising. In all cases, to be disoriented is to feel up in the air, and unsure of oneself, in more or less debilitating ways. Disorientations are not one-time events: they may be triggered by discrete events (e.g., the death of a loved one), but to be disoriented in this sense is a sustained experience. Less metaphorically, to be disoriented is to have difficulty making plans, feeling secure and confident in one's actions, or being able to go about one's daily life with ease. Think of the common feelings following the loss of a loved one or diagnosis of a serious illness: who am I now? How can I go on with my life? My home and job may not feel comfortable anymore. I may struggle to feel happy, and be constantly questioning myself and my decisions. As I discuss at length elsewhere, empirical research on, and first-person accounts of, the experiences of grief, serious illness, migration, coming out as queer, feminist consciousness raising, and racism are rich in their descriptions of what being disoriented can feel like. I mean the term 'disorientation' to capture a sense in which major life experiences can make it hard to know how go on in the sense of becoming unsure of how we should identify ourselves, what we should believe, what projects we should pursue, and what actions we should prioritize. 
As I have detailed at length in Disorientation and Moral Life, disorientations can be positive or negative, that is, helpful or harmful, in at least three senses.

First, disorientations can be triggered by both positive and negative life events. Certainly grief, serious illness, trauma and other devastations can cause people to be disoriented. These events can make it difficult to know how to go on with one's life - how or whether to continue in daily routines, relationships, or work, and indeed how to understand one's own identity. But so too can some more positive life events cause people to be disoriented. Migration (when desired), coming out as queer, feminist education, consciousness raising, and even such common events as becoming a parent or entering a new romantic relationship can be disorienting. These too can make one's old routines, identifications, and relational practices seem unfamiliar or undesirable, without yet introducing new practices in their place. So, while we might more commonly think of negative life events as being disorienting, positive left events can also make it difficult to know how to go on.

Second, while on my account disorientations are always 'sustained, difficult experiences that make it hard to go on', and so they are by definition strenuous, different disorientations can be experienced as more or less invigorating, challenging, or stretching rather than as exclusively heavy or burdensome. Consider how the disorientation of coming to terms with a job loss can be both frightening and also in some cases, if one's basic needs are still met, liberating and interesting. This is quite unlike the disorientations of grief which are more commonly depicted as persistently painful, and only less painful by degrees, over time - not typically interesting or playful. So, the qualitative experience of being disoriented can be more or less painful.

And third, disorientations can have both positive and negative effects, morally speaking. It is obviously true that disorientations can have negative effects - they can debilitate agents, cause breakdowns in moral agency, and make it not only difficult but indeed impossible to go on. Disorientations, when serious enough, can cause mental, emotional, or physical collapse, serious mental illnesses, and even put individuals at risk of self-harm. But I have argued at length (Harbin 2012, 2014a, 2014b, 2016), drawing on first person written accounts and qualitative research from psychology, sociology, social work, and other disciplines, that disorientations can have both negative and positive effects, morally speaking. They can, in some cases, and to different degrees, have effects such as prompting increased epistemic humility, sensitivity to vulnerability, and capacities to live unprepared. And as I have argued, in contexts with certain moral and political features that make these effects useful, such disorientations can be morally and politically productive.

I now want to suggest that experiences of fear can involve disorientations: sustained, difficult experiences that make it difficult to go on.

Consider how individuals may become newly fearful in ways which are disorienting. Even quickly resolved fearful events can be disorienting, like seeing one's dog running into the street, or hearing what sounds like a possible intruder in the night. But consider more prolonged cases where an individual has until a certain point felt secure, safe, or assured in some arena, and suddenly comes to feel that they are under threat. Many instances of recently acquired or amplified fears seem to fit in this category.

For instance, one source of fear that has been growing for some people in recent years is the fear of climate insecurity, as many of us are coming to recognize that we cannot take life on earth for granted in the way many of us have before. Populations are realizing the potential threat of water insecurity, food insecurity, and devastating weather events (flooding, tornadoes, hurricanes, etc.). This may be a significant source of fear for individuals as we feel unsure of 
how to prepare, how to anticipate the needs of our own and future generations, and what kinds of knowledge and skills we may need to cultivate now in order to survive shifts and insecurity in climate.

Or consider another example of prolonged fear: many have worries in response to recent threats to health care in the U.S. context. A federal policy instituted under former president Barack Obama required that all individuals acquire (either by purchasing, acquiring through their employer, or through government support) health insurance that would allow them to access at least basic health coverage, or be penalized. The 'Affordable Care Act' (so-called Obamacare) was a major shift in the landscape of U.S. society, as previously some $16 \%$ of the population lacked any health insurance, and millions more were dramatically underinsured. There were many problems with the Affordable Care Act - it certainly did not make health care truly affordable, as many individuals who were required to purchase health insurance could neither afford the most basic of insurance plans, nor even the fine they would pay if they opted to remain uninsured. Universal coverage was not achieved. But the arguable successes of the policy, including instituting some restrictions on a for-profit private insurance industry that could exclude individuals on the basis of they or a family member having pre-existing health conditions, were significant and life-saving. Under the new presidential administration, these advances have been threatened. In 2017 and 2018, the administration attempted to repeal the Affordable Care Act with no replacement, which would amount to loss of insurance for 20+ million Americans, hitting members of underserved populations (working class individuals, women and non-binary individuals, and racialized groups) hardest. $^{1}$

The response to this threat has been seismic. Many individuals with so-called 'pre-existing conditions' feared they would lose coverage when the insurance industry was once again permitted to exclude them (Goodnough and Abelson 2017). Many more would not be able to afford any variety of insurance. Annual and lifetime limits on insurance coverage would prevent even those with insurance from accessing care, and would drive some into medical bankruptcy. Fortunately, though part of the law has been changed, the wholesale plan to repeal Obamacare has not yet succeeded. Even so, the repeal attempts have caused widespread anxiety, fear, and alarm. ${ }^{2}$

Fear of losing one's health insurance can be deeply disorienting. It can make it difficult or impossible to feel one can go on in many realms of life. There is nothing that can assure individuals that the fear of losing access to health care is minor, or that it is livable. ${ }^{3}$ And this fear can be disorienting insofar as it calls into question many of one's regular assumptions and

\footnotetext{
${ }^{1}$ Robert Doherty of the American College of Physicians summarizes the likely effects of such a repeal as follows: "Despite its flaws, the ACA has achieved a historic reduction in the number of uninsured persons in the United States, with more than 9 out of 10 Americans having coverage and 22 million and counting getting their coverage from the ACA. Those who will be most affected by repeal include working-class people, women who are concerned about loss of coverage for contraception, and entrepreneurs with medical conditions who fear they will have to give up their start-ups for jobs that offer coverage - not to mention the many more people with preexisting conditions who may again find themselves turned away by insurers." (Doherty 2017, 145)

${ }^{2}$ As Yamada writes, "Although the ACA repeal attempts repeatedly failed during 2017 and early 2018, the Congressional deliberations over them were sources of public anxiety across the nation...These legislative outcomes have not been able to prevent widespread fear and anxiety over the possible loss of health insurance coverage for millions of Americans... Those with limited or no incomes, preexisting health conditions, or major ongoing health care expenses had special reason to be alarmed at the speed and lack of legislative due process driving these deliberations, much less the possible results." (Yamada 2018, early view online)

3 Journalist and writer Corbyn Hightower describes her personal experience of losing health insurance after losing her job: "There is never a time that you forget that your children are uninsured. You feel like running behind them in a half- crouch, arms extended, ready to catch the sudden stumble. ... When you don't have medical insurance, you never really feel like everything is going to be all right." (Hightower 2011)
} 
actions - what can one do to ensure one's family is safe if someone faces a serious illness or injury?

Threats of climate catastrophe and threats to health care are not the only serious threats affecting many individuals in recent years. I have written elsewhere about the growing realization that criminal justice systems are not trustworthy, even for those of us who have for the most part felt protected by them (Harbin 2017). We might also think of the prevalence of terror attacks, the detention and deportation of migrants, school shootings, the rise of vaccine-preventable diseases, and so on.

\subsection{Experiences of Fear Can Be Orienting}

While some experiences of fear can be disorienting, being disruptive to our processes of decision making, emotion regulation, and relating to others, in other cases, experiences of fear can in fact be very orienting.

By 'orientation' I mean not literal orientation in space, but rather the parallel to disorientation: if disorientation in my sense means a sustained difficult experience that makes it hard to go on, being oriented is to feel at ease emotionally, physically, and mentally - feeling secure in one's capacities to understand, think, and plan, and likely confident or assured in one's capacities for decision making. I elsewhere relate the feeling of orientedness to a feeling of 'resolve': a sense of security, decisiveness, clarity and wholeheartedness (Harbin 2016, 37). Concretely, in everyday life, this might amount to a sense of contentment and not questioning one's decisions: the oriented person is at ease in their home routines, in workplace, in relationships, and they have a sense of emotional peace.

We can see that, just as disorientations could be both negative and positive, so too can orientedness be both negative and positive.

Just like disorientations, orientedness can be triggered by both positive and negative life events. A positive life accomplishment like completing a degree or getting a new job or entering a new relationship can spur feelings of sureness, decisiveness or clarity. So too can negative life events like a diagnosis or job loss spur determination, clarity, and resolve: for instance, one might gain single-minded commitment to improving one's health or proving one's past employers wrong. Orientedness can also feel both positive and negative. Feeling wholehearted or secure is very often a pleasant feeling. But it is also possible that feeling too oriented - too inflexible, too rigidly occupied with particular goals - can feel stifling or boring. And orientedness can have both positive and negative moral effects. Being clearly and consistently resolved to act responsibly and care for others is obviously morally promising. But one can also be oriented in dangerous ways, for instance, towards maximizing my own profit at the expense of others' wellbeing.

Now to return to the connection between fear and feeling oriented. Some recent research has shown that fear can "promote systematic information-processing; that is, more careful analysis of information... Fear can make perceivers consider information more carefully and be more influenced by it" (Hunsinger 2010, 7; see also Bohner and Weinerth 2001; Parker and Isbell 2010). Being fearful can crystallize for individuals what to think, or how to act, and in some cases, may even have these effects before it is clear that these ways of thinking or acting are actually best.

Experiences of fear might be orienting when they help individuals become more decisive or confident about their actions. For instance, for those with some religious backgrounds, the fear of a deity's judgment and potential punishment may be a longstanding fear that informs one's 
basic commitments and daily life. This fear may be orienting: it helps an individual feel more decisive about which actions to pursue (those that will align with that deity's commandments), which to avoid (those that violate such commandments), and may help her feel directed, clearheaded, and confident that either she is living well or living badly. Likewise, other fears can be orienting. For example, if an individual has always been fearful of a certain group of people, they can feel oriented in their interactions with that group. It can seem clear that they should avoid and not trust members of that group. For example, a woman who experienced sexual violence perpetrated by a man may be fearful of men in a way which orients her towards always avoiding them. Or, in North America, as well as elsewhere, a Black man may be fearful of police in ways which orient him towards avoiding them, practicing extra vigilance in interactions with them, and teaching his children to be wary of police at all times. His fear has developed in a social context where he knows that Black men are regularly harmed and in some cases killed by the police, and such fear is orienting: it tells him what to believe, and what to do.

Differentiating the features of situations where experiences of fear are likely to be disorienting versus those which are likely to be orienting would require more empirical investigation and is not my intent here. My goal for now is simply to have shown that there are experiences of fear which are disorienting, and others that are orienting, though not all experiences of fear are one or the other. Having established this, we can now consider how fears might be used to disorient, or re-orient, others.

\section{Experiences of Fear Can Be Used to Orient or Disorient Others}

We have seen that experiences of fear can be either orienting, directing or honing our perceptions, clarifying how we should act and go on in our lives, or disorienting, making it unclear how to do so. Now add to this point a further layer: these disorienting or orienting features of fear, while not always intentionally brought about, can be cultivated by people with the express purpose of subjecting others to them. In other words, experiences of fear can be generated and used as tools with the goal of disorienting or orienting people.

Consider everyday cases where individuals attempt to make others feel fearful of something in order to manipulate or direct their actions. In some cases, experiences of fear are deliberately cultivated in order to orient others. Imagine the case of the selfish cousin. You and I are cousins. I have been in a long conflict with another one of our shared family members, and I want to bring more family members onto $m y$ side of the fight. With that goal in mind, I try to make you fearful about the family member with whom I am in conflict, perhaps even telling outright lies about them. My hope is to orient you through manipulating you into feeling fearful: I want to move you away from trusting them and towards taking my side. I do not only want you to believe me and not them-I want you to feel confident, assured, decisive, and at home being on my side, rather than theirs.

On the flip side, consider cases where experiences of fear are deliberately cultivated in order to disorient others. These are cases where individuals attempt to make others feel fearful of something in order to make it hard for them to know how to go on. Consider the case of the jealous father: imagine I am the single father of a grown daughter who considering getting engaged to her long-term boyfriend, but I worry that marriage will take her further away from me. When she confides in me that, though she has no reason to think so, she worries her partner will abandon her in the future, instead of reassuring her, from selfish intentions, I try to fan those worries into greater fears, and suggest that she should reconsider marrying, or even 
remaining in the relationship with this man. These fears, nascent already in her but deliberately enlarged by me, might cause my daughter to feel unsure of how to go on - she may become disoriented.

We might think of various other cases of individuals trying to make others feel fearful in order to disorient them. Imagine I have a friend who is considering becoming a parent but I want them to continue living a childfree lifestyle as I plan to, so I try to make them fear what would happen if they became a parent, perhaps enough to make them unsure how to go on. Or imagine I am a possessive boyfriend who does not want my girlfriend to apply for a promotion at work because I do not think women should be in positions of power and so I try to convince her that she is actually incompetent and to fear that she will inevitably fail and that all her coworkers and bosses will laugh at her, blame her, or even fire her. If I succeed, this may cause her to question herself and her professional identity - in other words, it may be disorienting.

Note that these are cases where someone deliberately cultivates fears in others (or capitalizes on their own existing nascent fears) in order to disorient them or to shift their orientations. Surely we can also think of cases in which someone deliberately cultivates fear in another person without deliberately intending to disorient or orient them - perhaps the fear cultivator just wanted to intimidate or bully. The moral evaluation of these cases might be different than the cases I have illustrated, which demonstrate deliberate actions both to cultivate fear and thereby to disorient/orient.

Before we move on, also note that there are plenty of cases where fear is either disorienting or re-orienting that are not the result of the deliberate manipulations of others. Experiences of fear can happen without anyone deliberately bringing them about, and such experiences can be either orienting or disorienting. And there are also cases where attempts to deliberately bring fears about with the goal of orienting or disorienting others do not produce the desired results. The agent who was the target of the attempt may not become fearful at all, or not in a way that is particularly orienting or disorienting. In others words, efforts to trigger fears with the goal of orienting or disorienting some other are not reliably effective.

\section{Moral Evaluation of the Use of Fear as a Tool}

So far we have established that there are cases where some people cultivate fear in others with the goal of orienting or disorienting them. We have established this in a number of steps: characterizing what fears are, how fears can disorient agents, how fears can orient agents, and how fears can be used to either disorient or orient agents. I think these are interesting and not uncommon cases. Elsewhere I draw out the political implications of such uses of fear as tools suffice it to say, it should not be difficult to imagine authoritarian inductions of fear for political ends. My goal now is not to delve into the political implications, but rather to remain at the level of moral evaluation of such cases as we have described, at the interpersonal level. Our moral evaluation of these cases might then inform a future analysis of complex political landscapes.

So, how can we morally evaluate cases of cultivating fear in others with the goal of orienting or disorienting them? In order to do so, I suggest we must morally evaluate two parts of the action: (1) actions to cultivate fear; and (2) actions to orient or disorient others.

Notice that the cases I consider in section two are all ones where agents deliberately cultivated fear in others. In the cases that interest me, the deliberateness of both the cultivation of fear and fear's disorienting/orienting effects matters for the moral evaluation of these actions, because in these cases we must evaluate not only the intention to cause fear (and its 
inherent suffering and epistemic effects), but also the intention to orient/disorient the fearful agent towards or away from prospective actions (e.g., orienting the cousin towards siding with me, or disorienting the girlfriend in light of her future career). The intention to cause these effects makes a moral difference in the same way that killing someone intentionally is morally different from killing someone accidentally. I will leave aside in this moral evaluation cases where some action of mine accidentally induces fear in another in a way that accidentally disorients or orients them.

\subsection{Actions to Cultivate Fear}

As noted in section one, to fear in a serious sense (i.e., not in the context of entertainment) is to suffer. So to cause someone to fear - regardless of whether that fear has eventual bearing on disorientation or orientation - is to cause suffering. As we also saw, to fear in a serious sense can be epistemically damaging. It can skew one's beliefs to be overly attentive to risks, can damage processes of decision-making, and so on.

Deliberate actions which cause suffering are prima facie morally troubling and potentially blameworthy. Of course, in some cases, suffering is an unfortunate but necessary part of an action that is nonetheless morally acceptable or praiseworthy: an infant suffers when she receives a vaccine but the parent and health care provider's actions to provide the vaccine are morally praiseworthy. The small bit of suffering of getting a jab now is justified in light of the protection the vaccine affords against greater possible suffering of a serious illness in the future. So not all actions which cause suffering are blameworthy, but they must be justified. Actions which cause suffering without worthwhile goals (like a child's health) are not morally neutral: they are blameworthy. If an action causes only a small amount of unjustified suffering (e.g., pinning your brother down on the floor and twisting his arm painfully), it is blameworthy, but less so than an action that causes a great amount of unjustified suffering (e.g., killing a woman by drunk driving). So too, actions which cause a small amount of unjustified fear and thereby a small amount of unjustified suffering will be blameworthy, and actions which cause great unjustified fears and thereby a great amount of unjustified suffering will be more blameworthy.

Actions which cause epistemic damage are also prima facie blameworthy. Of course, these too must be understood in the context of the whole: actions might cause epistemic damage and nonetheless be justified if, on balance, they have more positive effects. For instance, it might cause epistemic damage for me to lie to my toddler about something minor (e.g., telling her that I am going to the doctor for an easy checkup, rather than telling her the whole truth, that I will undergo a painful minor procedure there), but if that lie is worthwhile for the other positive effects (e.g., preventing her from being overly burdened by worry), then the epistemic damage I cause (i.e., causing her to have inaccurate beliefs) may be justified. But in the absence of counterbalancing factors, actions which cause epistemic damage are morally blameworthy. So, the potential epistemic damages caused by cultivating fear in someone e.g., causing them to be overly attentive to risk and (at least potentially) insufficiently attentive to likelihoods of positive outcomes - will be morally blameworthy, in the absence of justification for causing that fear.

This raises the question, what are cases when it may be justified to cultivate fear (thereby subjecting them to the suffering and potential epistemic damage it involves) in another person? If I judge a person to be insufficiently fearful of something, am I justified in attempting to make them more fearful? When we begin to discuss when an agent might be justified in 
cultivating fears (and their accompanying suffering and potential damages) in others, questions of paternalism arise.

Paternalism has been defined by Gerald Dworkin as "the interference of a state or individual with another person, against their will, and defended or motivated by a claim that the person interfered with will be better off or protected from harm" (Dworkin 2017). Key here is that the interferer acts in a way that they believe will be good for the person with whom they interfere. Of course, the interferer may not actually know what is best for the other person. So long as they act upon their beliefs about what is good for the other, this counts as paternalistic. As Danny Scoccia explains, "The paternalist believes that her interference benefits her target and that this benefit justifies the interference" (Scoccia 2018). Actions to cultivate fears in others can certainly be done from paternalistic motives. What we will morally evaluate here is the action - the interference - rather than the interferer's beliefs.

It turns out that in many cases that immediately come to mind, what might seem to justify my action to make another person feel fearful is not a problem of their lack of fear per se, but rather the actions or inactions their lack of fear might motivate. It seems difficult to make the case for the induction of fear being justified simply because some person should feel more fearful than they do. It seems that a person who is simply not fearful of some danger may rightly feel whatever lack of fear they feel. For instance, perhaps a friend does not feel fearful of COVID-19. As long as they act responsibly - taking sufficient care with their own and others' health - perhaps we cannot insist that they ought to feel fearful. But if they fail to act with sufficient concern for their own or others' health and wellbeing, of course they can then be morally blameworthy for their failure to act. In many cases, what might seem to justify my attempting to cause fear in another person is a desire to have them act or come to act more confidently in a certain way - that is, to orient or disorient them by making them fearful. Fear is a great motivator, and perhaps in some cases, the feeling of fear is the most direct or only path to motivating another person to act in a way that is (or is what I judge to be) best for them.

We will evaluate these instances of cultivating fear in order to orient or disorient in a moment. Recall, the question so far is just about the moral evaluation of actions to cultivate fear itself in another person (not yet actions to cultivate fear in order to disorient or orient that person's action), and so far, we see that there are complex questions about when or how it may be justified to cultivate fear in another. Even if there is some case to be made for the other person as being insufficiently fearful, if we leave aside the question of being justified in motivating that person to act in certain ways, it seems that cultivating fear in another person, and subjecting them to the suffering and potential epistemic damage fear involves, is morally blameworthy in the absence of counterbalancing considerations.

\subsection{Actions to Disorient or Orient Others}

In order to morally evaluate cases of cultivating fear in others with the goal of orienting or disorienting them, we said we must morally evaluate two parts of the action: (1) actions to cultivate fear; and (2) actions to orient or disorient others. Now that we have discussed (1), we can turn to (2). What is the moral status of actions to disorient or orient others?

The first thing to note is that I have elsewhere argued that comparable actions - to induce non-fear related disorientations in others - are not morally required. I have argued (Harbin 2018) that, even though I argue extensively for the potential moral and political benefits of disorientations, agents do not typically have a responsibility to actively seek or cause disorientations for themselves or others. There are plenty of disorientations that occur without 
anyone actively seeking them out or creating them for each other. Further, we may not be successful if we attempt to create or force disorientations deliberately.

More difficult is the question of moral acceptability. Is it morally acceptable to cultivate emotions (like fear) in others with the express goal of causing them to turn towards or away from certain actions and ways of being?

On some views, such actions (to cultivate emotions in others with the goal of motivating them to act or be in some way) could be considered coercion. But if we follow Scott Anderson's fairly broad definition of coercion as "the use of an ability some agents have to enforce their decisions about what another will or will not do, where the sense of enforceability here is exemplified by the use of force, violence, and the threats thereof to constrain, disable, harm, or undermine an agent's ability to act" (Anderson 2010, 6), I do not think these actions are best understood as coercive, but rather merely as manipulative. They do not so much involve enforceability or threat as examples of coercion more commonly do, but rather they wield the power generated by a relationship to attempt to cultivate feelings of fear and thereby to prompt orientations or disorientations.

The moral status of attempts to cultivate such emotions depends a great deal on the specifics of the intended outcomes. Does the person cultivating the emotions in others believe that doing so will motivate those persons to act in ways that are good for them?

The cultivators of fear in the cases of section two are wrong to cause suffering in others for reasons exclusively connected to their own desires. The possessive boyfriend presents a case where fear is cultivated in order to orient/disorient with malicious intent (i.e., to prevent women in general and his girlfriend in particular from occupying positions of power). It does not involve action done from a spirit of beneficence or care for the person who is made to be fearful. It is morally blameworthy to cause fear (and thereby suffering and potential epistemic damage) in the absence of counterbalancing considerations, and so it is morally blameworthy to attempt to orient or disorient others' actions with malicious goals in mind. Even if the case somehow accidentally managed to benefit the girlfriend - by some stretch of the imagination, consider an instance in which the promotions would have actually been bad for her in some legitimate sense, for instance causing her to be wrongly held responsible for some action of the company and unlikely to ever work again - the possessive boyfriend's action itself intended to harm her and cannot be defended as morally acceptable.

Of course, it is possible that a person could attempt to cultivate fear and thereby orientation/ disorientation in another from not exactly malicious but instead merely self-interested intent. Arguably, the selfish cousin, jealous father, and childfree friend cases are of this type. A person attempts to cultivate fear from the motive of self-interest and thereby to orient another person towards confidently embodying a different set of actions or way of being. While these may be less blameworthy than the malicious case of the possessive boyfriend, since the outcome is not meant to actively harm the fearer, they are still cases of causing fear (and thereby suffering and potential epistemic damage) and either likely or at least potential harms to those within whom fear is cultivated, without counterbalancing considerations sufficient to justify causing such fears. The selfish desires of the cousin, father, and friend do not suffice to justify causing such fears and the likely or potential harms that accompany them. And so these too are morally blameworthy attempts to orient or disorient others' actions by causing fear.

Could beneficent cases exist? Could fears be deliberately wielded paternalistically in ways which disorient or orient others, where the paternalistic actor at least believes that disorientations/re-orientations will be in the best interests of the fearful one? Could the disorientations/orientations ever actually be in that person's best interest? 
It is not impossible that fears could be cultivated or enlarged with the goal of orienting or disorienting others with beneficent intent, and in ways which may in fact be in the interests of the fearful party. Consider, for instance, a case where I try to make my younger teenage sibling frightened enough of hard drugs that they become strongly oriented away from taking them (e.g., so that they decisively and confidently embody a stance against taking recreational drugs, as is the tactic of many 'scared straight' programs). In such a case, I paternalistically cultivate fear as a tool in order to orient my sibling towards a path that I think is good for them, and towards a path which may in fact be good for them. Or consider a case where I see a friend about to embark on a very risky business venture, and while I do not know what they should do instead, I believe that they will be vulnerable to harm if they continue with the business plan. I might in such a case try to make them frightened enough of possible bad outcomes that they become unsure of how to go on. This might constitute paternalistically cultivating fear as a tool in order to disorient my friend; they may come to feel adrift without plans for their life, and like they do not know how to go on. Even so, I may believe this disorientation to be, and it may in fact be, better for my friend than the risky alternative.

Quandaries of paternalism are of course always morally complicated and the subject of substantial debate. If I am subjected to paternalism in ways which ultimately benefit me, does that excuse the potential harm of the paternalistic acts? I will not attempt to settle this question here, rather, I simply want to allow that it is possible for fears to be deliberately used to orient/ disorient in ways which are perceived as being, or in ways which may actually be, in the best interests of the would-be fearful person. This means that there are some cases in which it may be morally acceptable to cultivate fear in order to orient or disorient another person: the moral acceptability of these actions will depend on the actual outcomes for the would-be fearful person.

\section{Conclusion: Fear and Unmanipulability}

We have considered a number of dimensions of the use of fear as a tool to orient or disorient others. My goal has been to establish some main characteristics of experiences of serious fears: they are difficult, they involve suffering, they can cause epistemic damages, and they can be disorienting or orienting. As we have seen, experiences of fear can be used as tools to orient or disorient others, and attempts to cultivate fears in others with the goal of orienting or disorienting them are morally complicated. We have evaluated the moral status of actions to cultivate fears themselves, and seen that cultivating fear in another person, and subjecting them to the suffering and potential epistemic damage fear involves, is morally blameworthy in the absence of counterbalancing considerations. We have evaluated the moral status of actions to deliberately orient or disorient others and seen that doing so is unacceptable from malicious or self-interested and otherwise unjustified motives, though it may be morally acceptable to do so from paternalistic motives, depending on the actual outcomes for the would-be fearful person.

I want to conclude with a note which further complicates all of this. As I have established elsewhere, effects of attempts to disorient or forcefully reorient agents can be surprising. While I believe that fear is often used as a tool to orient or disorient others, those who attempt to cultivate fear in others with the goal of orienting or disorienting them may find that their efforts have unexpected results. In some cases, would-be fearers do not become fearful. In other cases, fear neither orients nor disorients. Would-be fearers are not predictably manipulatable, nor are the effects of their experiences of fear foreseeable. For this reason, along with 
the others I have given here, agents should proceed with extreme caution with the use of fear as a tool to disorient or orient. My hope is that understanding the potential dynamics of disorientation and shifts in orientation at play in some experiences of fear will open up the conversation about how fears could affect individuals without necessarily making them more susceptible to manipulation.

Acknowledgements For helpful feedback and suggestions I thank participants at the Workshop on the Value of Disruptive Moments for our Lives at the University of Antwerp, May 2018, Michael Doan and two anonymous journal referees.

\section{References}

Anderson S (2010) The enforcement approach to coercion. J Ethics Soc Philos 5:1-31

Bohner G, Weinerth T (2001) Negative affect can increase or decrease message scrutiny: the affect interpretation hypothesis. Personal Soc Psychol Bull 27:1417-1428

Chanel O, Chichilnisky G (2009) The influence of fear in decisions: experimental evidence. J Risk Uncertain 39(3):271-298

Doherty R (2017) Demise of the affordable care act? Not so fast. Ann Intern Med 166:144-145. https://oi. org/10.7326/M16-2728

Dworkin G (2017) "Paternalism." Stanford Encyclopedia of Philosophy. https://plato.stanford. edu/entries/paternalism/ (Accessed March 26 2020)

Goodnough A, Abelson R (2017) "Patients who reply on Obamacare protections are worried." New York Times https://www.nytimes.com/2017/05/02/health/obamacarepatients-preexisting-conditions.html

Harbin, A (2012) Bodily disorientation and moral change hypatia 27(2):261-280

Harbin, A (2014a) Disorientation and the medicalization of struggle. Int J Fem Approaches Bioeth 7(1):99-121

Harbin, A (2014b) The Disorientations of Acting against Injustice. J Soc Philos 45.2:162-181

Harbin A (2016) Disorientation and moral life. Oxford University Press, New York

Harbin A (2017) Safety and Sacrifice. Ethics and Social Welfare 11(2):163-176

Harbin A (2018) Response to commentaries on Disorientation and Moral Life. Feminist Philosophy Quarterly 4(2)

Hartley C, Phelps E (2012) Anxiety and decision-making. Biol Psychiatry 72:113-118

Heilman M, Criasan L, Houser D, Miclea M, Miu A (2010) Emotion regulation and decision making under risk and uncertainty. Emotion 10(2):257-265

Hightower C (2011) "Will everything be alright?" http://corbynhightower.com/ will- everything- be- all- right/

Hunsinger M (2010) "Threat on the mind: The impact of incidental fear on race bias in rapid decision-making." Doctoral Dissertations Available from Proquest. AAI3427537. https://scholarworks.umass. edu/dissertations/AAI3427537

Johnston E, Olson L (2015) The feeling brain: the biology and psychology of emotions. W.W. Norton and Company, New York

LeDoux J (1996) The emotional brain. Simon and Schuster, New York

Lerner JS, Keltner D (2001) Fear, anger, and risk. J Pers Soc Psychol 81(1):146-159

Parker MT, Isbell LM (2010) How I vote depends on how I feel: the differential impact of anger and fear on political information processing. Psychol Sci 21(4):548-550

Phelps EA, Ling S, Carrasco M (2006) Emotion facilitates perception and potentiates the perceptual benefits of attention. Psychol Sci 17(4):292-299

Ray SL, Vanstone M (2009) The impact of PTSD on veterans' family relationships: an interpretive phenomenological inquiry. Int J Nurs Stud 46(6):838-847

Scoccia D (2018) "The concept of paternalism." The Routledge Handbook of the Philosophy of Paternalism. Ed. Kalle Grill and Jason Hanna

Skitka LJ, Bauman CW, Aramovich NP, Morgan GS (2006) Confrontational and preventative policy responses to terrorism: anger wants a fight and fear wants 'them' to go away. Basic Appl Soc Psychol 28(4):375-384

Yamada DC (2018) On anger, shock, fear, and trauma: therapeutic jurisprudence as a response to dignity denials in public policy. Int J Law Psychiatry Early View Online 63:35-44. https://doi.org/10.1016/j.ijlp.2018.06.009

Publisher's Note Springer Nature remains neutral with regard to jurisdictional claims in published maps and institutional affiliations. 